\title{
Competências organizacionais, trajetória tecnológica e aprendizado local na agricultura: o paradoxo de Prebisch *
}

\author{
José Eustáquio Ribeiro Vieira Filho \\ José Maria Ferreira Jardim da Silveira ${ }^{* * *}$
}

\begin{abstract}
Resumo
O tema da inovação tecnológica na agricultura é tratado na literatura econômica primordialmente no debate sobre o desenvolvimento econômico, com destaque dado aos problemas dos países periféricos. Para entender a evolução do moderno setor agrícola, é necessário um enfoque mais amplo de debate, o qual remete ao paradoxo de Prebisch: o setor agrícola é capaz de gerar progresso técnico e valor agregado, bem como promover o desenvolvimento de regiões agroexportadoras. A inovação tecnológica não implica somente na aquisição de insumos modernos, mas na gestão do conhecimento tácito e específico incorporado nas tecnologias. A capacidade de inovar depende do gerenciamento produtivo dos agricultores. O produtor investe no intuito de incorporar novas tecnologias, aumentar o aprendizado e ampliar a capacidade de absorção de conhecimento. $\mathrm{O}$ estudo aponta para a importância das fontes externas de conhecimento, seja em termos do aprendizado pela experiência ou do efeito de transbordamento da acumulação de conhecimento em rede.
\end{abstract}

Palavras-chave: Inovação; Trajetória tecnológica; Aprendizado; Economia agrícola; Desenvolvimento.

\begin{abstract}
Organizational skills, technological trajectory and local learning in agriculture: the Prebisch paradox

The theme of technological innovation in agriculture is largely treated in the economic literature in the debate on economic development, with an emphasis on the problems of the peripheral countries. To understand the evolution of modern agriculture, a thorough analysis referring to the Prebisch paradox, is required: the agricultural sector is capable of generating technological progress and added value, as well as promoting the development of agro-export regions. Technological innovation involves not only the acquisition of modern inputs, but also the management of tacit and specific knowledge embodied in technologies. The ability to innovate depends on the degree of the productive management of each farmer. The producer invests in order to incorporate new technologies, increase learning and expand the absorptive capacity of knowledge. This study shows the importance of external sources of knowledge, in terms of learning by experience and spillover effects on the business network.
\end{abstract}

Keywords: Innovation; Technological trajectory; Learning; Agricultural economics; Development.

* Artigo recebido em 22 de dezembro de 2014 e aprovado em 23 de junho de 2016

** Técnico de Planejamento e Pesquisa do Instituto de Pesquisa Econômica Aplicada (Ipea) / Secretário executivo da Sociedade Brasileira de Economia, Administração e Sociologia Rural ( $\underline{\text { Sober }}$ / Professor do Programa de Pós-graduação em Agronegócio da Universidade de Brasília (Propaga/UnB), Brasília, DF, Brasil. E-mail: jose.vieira@ipea.gov.br.

${ }^{* * *}$ Professor Associado do Instituto de Economia (IE) da Universidade Estadual de Campinas (Unicamp). Pesquisador do Núcleo de Economia Agricultura e Ambiental (NEA) do IE e do Núcleo Interdisciplinar de Planejamento Energético (NIPE). E-mail: jmsilv52@gmail.com. 
JEL Q16, O3, O4.

\section{Introdução}

O tema da inovação tecnológica na agricultura vem sendo tratado na literatura econômica primordialmente no debate sobre o desenvolvimento econômico, com destaque dado aos problemas dos países periféricos. A discussão é mais extensa quando se inclui questões da renda dos pequenos agricultores, da segurança alimentar e da sustentabilidade ambiental. Além disso, o setor agrícola contribui com a geração de divisas que alavanca os processos de financiamento das atividades industriais, com a redução dos preços dos alimentos da cesta básica que promove redistribuição de renda e com a construção da infraestrutura urbana de países em desenvolvimento.

A tese estruturalista de Raúl Prebisch, desde 1950, compreendia a dinâmica do desenvolvimento das economias de industrialização tardia. O subdesenvolvimento da América Latina era explicado pela dependência das exportações de matérias-primas, enquanto que aos países centrais cabiam as exportações de bens industrializados (Prebisch, 2000). No comércio internacional, as economias periféricas transferiam renda aos países desenvolvidos, inibindo sua própria industrialização. Esse ponto foi uma das justificativas para estimular o processo de "substituição de importações" (Tavares, 1972), bem como elevar o protecionismo, que pretendia reduzir as importações de manufaturas para promover a produção doméstica.

Todavia, para entender a evolução do setor agrícola, é necessário um enfoque mais amplo de debate, o qual remete ao paradoxo de Prebisch: o setor agrícola é capaz de gerar progresso técnico e valor agregado, bem como promover o desenvolvimento de regiões agroexportadoras ao mesmo tempo em que se têm termos de trocas favoráveis. O processo de inovação - no conceito amplo definido por Schumpeter - se insere na análise de desenvolvimento econômico, uma vez que as transformações socioeconômicas ocorrem em grande parte por processos de industrialização e urbanização. Desse ponto de vista, podem-se comparar sociedades em que a agricultura (e a pobreza no campo, como mostra World Bank, 2008) vai perdendo importância relativa. Porém, no conjunto da sociedade, a queda da participação da agricultura no produto interno bruto (PIB) requer maior atenção.

Nota-se que há papel de destaque para os processos que elevam a produtividade da produção agropecuária, processos que se relacionam às inovações organizacionais e, principalmente, às tecnológicas. $\mathrm{O}$ choque dos preços agrícolas na década passada, ainda que possa ter sido determinado por processos de especulação financeira e efeitos indiretos do uso do solo (visando à produção de energias renováveis), chamou a atenção para os baixos estoques de produtos agrícolas essenciais, para a polarização macrorregional da produção agrícola (cerca 
de $90 \%$ da proteína que abastece a cadeia de carnes do mundo vem das Américas) e para a enorme heterogeneidade da produção (Fornazier; Vieira Filho, 2012; Vieira Filho; Santos; Fornazier, 2013; Vieira Filho, 2013).

Existiriam elementos teóricos que permitem entender quais variáveis guiam os processos de mudança no conjunto das atividades econômicas, que em muito superam a divisão da economia nos três setores? Estariam os processos de inovação tecnológica e organizacionais da agricultura submetidos à intencionalidade das ações coletivas, tendo muito pouco peso o espírito inovador, a competição, e as vantagens de monopólio temporário? Tais questionamentos definem duas ideias centrais. A primeira é que, tendo a firma como unidade de decisão, as atividades agrícolas constituem uma espécie de resíduo histórico a ser superado, principalmente pela fragilidade tecnológica da produção agrícola. A segunda, desenvolvida na tradição europeia, encara as atividades agropecuárias como parte de um processo de valorização do território (Mazoyer; Roudart, 2001; Favareto, 2007).

De um lado, entende-se que as atividades agrícolas (que incluem a indústria de processamento de alimentos) são "de baixa tecnologia", o que leva às sugestões de políticas voltadas ao desenvolvimento científico e tecnológico como meio de superação desta dependência à economia de recursos naturais. Aplica-se tal formulação à situação da América Latina de distanciamento dos NIC's asiáticos (New Industrialized Countries) em termos do crescimento industrial e por sua crescente dependência das importações da China de matérias-primas. De outro, percebe-se a atividade agrícola no contexto da preservação do território, o que demanda, curiosamente, subsídios e formas de apoio extremamente custosas, além de implicar "dependência de caminho", uma vez que qualquer proposta de reforma do sistema passa a enfrentar a resistência dos agricultores. A realidade da agricultura subsidiada e protegida em países como os EUA e a Europa daria suporte à ideia de que a lucratividade da agricultura de mercado não se sustentaria no agregado ${ }^{1}$.

De certa forma, as duas ideias se complementam: agricultura como atividade produtiva de mercado é algo a ser superado. Esse raciocínio tem implicações para a formulação de políticas. Recorre-se a uma visão histórica de superação do papel da agricultura na geração de produto e emprego, que é correta. Nenhum país se desenvolveu baseado apenas em agricultura. Todavia, contraditoriamente, mantémse a visão romântica de agricultura familiar, reforçada pela questão do desenvolvimento sustentável e pela crítica à monocultura capitalista, uma generalização da experiência histórica francesa (Favareto, 2007; Mazoyer; Rodart, 2001).

Paradyil (2003) relaciona a coordenação e iniciativas voltadas à geração e difusão de inovações na agricultura ao processo de alinhamento político dos países

(1) World Bank (2008), para uma discussão. 
pobres e em desenvolvimento no que chama período pós-colonial. Wright (2012) aponta para a importância das ações coordenadas entre organizações internacionais e instituições locais e como suas articulações interferem no padrão de inovação na agricultura e no impacto social. As inovações de mais amplo alcance geram maior benefício social, mas estas dependem de ações coletivas coordenadas internacionalmente. Os dois autores, op. cit., mesmo com visões distintas, convergem em apontar momentos cruciais para o desenvolvimento dos países em que uma ação institucional de significativo impacto se consolida, transformando os padrões produtivos da agricultura.

O presente trabalho procura apresentar uma interpretação para as evidências encontradas na literatura econômica e na experiência de alguns países (particularmente, Brasil, Argentina e alguns casos isolados na América Latina e no mundo). A inovação tecnológica nas cadeias agroindustriais gera uma dinâmica diferenciada. Esta diferenciação resulta em heterogeneidade regional, que permite a apropriação de ganhos de inovação sem que ocorram mecanismos caracterizados por Cochrane (1958) como treadmill ${ }^{2}$. Entretanto, a heterogeneidade estrutural, como visto por Pinto (1970), Nohlen e Sturm (1982), Katz (2000), Cimoli (2005), Cimoli, Primi e Pugno (2006), Sunkel e Infante (2009), Cepal (2010), Fornazier e Vieira Filho (2012) e Vieira Filho (2013), inviabiliza o processo competitivo e gerador de tecnologia, por entender que o crescimento sustentável com equidade se associa à superação do elevado diferencial de produtividade intra e intersetoriais. A heterogeneidade é fruto do processo de competição e busca tecnológica; porém, quando se torna estrutural, o desenvolvimento inclusivo se compromete.

Para tanto, organizam-se três seções, além desta breve introdução. $\mathrm{Na}$ primeira, procura-se problematizar e identificar "hipóteses" que possam guiar o texto. Na segunda, apresenta-se a noção de trajetória tecnológica ampliada (que difere do termo regime técnico econômico), enfatizando a conjugação entre formas organizacionais, inovação e aprendizado localizado, como forma de aplicar conceitos neoschumpeterianos à agricultura. Na terceira, tem-se a discussão da importância do aprendizado localizado na dinâmica agrícola. Por fim, seguem-se as considerações.

\section{Inovação tecnológica e organizações: a agricultura e o paradoxo de Prebisch}

(2) Segundo Cochrane (1958), a explicação para a contínua introdução de inovações na agricultura estaria no mecanismo competitivo que faria com que os ganhos de inovação fossem transferidos quase que integralmente aos consumidores, reduzindo preços e demandando introdução de inovações. O fato de uma tonelada de soja ter um preço próximo à mesma quantidade de circuitos integrados revela que tal mecanismo também poderia descrever a indústria de informática, sem mesmo invalidar o trabalho seminal de Dosi (1984) sobre a indústria dos semicondutores. 
A perspectiva da organização e do aprendizado organizacional e sua instrumentalização mudam o foco posto pela visão neoschumpeteriana tradicional (Dosi, 1988), da habilidade e esperteza em realizar a competição com as firmas rivais para a busca de resolver problemas de governança das organizações e de motivar a introdução de estratégias, visando ganhos continuados em capacitação (Dosi; Faillo; Marengo, 2003). A complexa relação entre a mudança tecnológica, a competição entre firmas e as variadas formas organizacionais fornece elementos básicos para o entendimento do progresso técnico, ganhos de competitividade e crescimento econômico (Cimoli, 2005). A preocupação com os arranjos institucionais manifestase tanto pelos sistemas nacionais de inovação quanto pelas especificidades setoriais relativas ao processo de inovação e imitação tecnológica das firmas (Breschi; Malerba; Orsenigo, 2000; Malerba, 2002).

É possível destacar a relação entre as várias formas organizacionais intra e interfirmas para gerir competências, capacitações e acumulação de conhecimento. As corporações, por exemplo, são caracterizadas como organizações complexas que combinam a gestão de recursos, tangíveis e intangíveis, com o domínio de tecnologias em parte corporificadas em equipamentos e instalações (Teece et al., 1997; Foss; Foss, 2000; Aoki, 2007). Há uma complexa relação entre tecnologias, formas organizacionais e desempenho das firmas, considerando: “a) os processos de aprendizado; b) a ocorrência de dependência de caminho; c) as oportunidades tecnológicas que não necessariamente são criadas pela firma; d) os ambientes seletivos; e) a dotação das firmas, principalmente na configuração de ativos complementares" (Dosi; Faillo; Marengo, 2003, p. 23).

Na agricultura, esta perspectiva se dá em vários níveis, sendo que o mais abrangente interage com o mais específico, sem que haja hierarquia, mas sim diferenças temáticas ${ }^{3}$. Um nível mais amplo, voltado à importância social da agricultura, baseada na segurança alimentar (Belik, 2004; Paradyil, 1992), implica tomar decisões com impacto macroeconômico, como definir política de importação de alimentos (grãos, principalmente), de formação de estoques reguladores (indesejável à agricultura local), de subsídios (criticada por distorcer preços relativos da economia) e de aumento da produção e da produtividade agrícola (com investimentos em infraestrutura, como estradas, ferrovias, portos, armazéns e laboratórios de pesquisa). Portanto, não se trata de um único tipo de preocupação. No caso europeu, pode-se até afirmar que houve uma despreocupação com a

(3) A ideia de níveis é inspirada no trabalho de Aoki (2007) e de Brousseau e Raynaud (2008). São níveis de abstração que não implicam em determinação hierárquica, ou seja, que o nível mais amplo determine o meso e, por conseguinte, o micro. Não se altera a concepção schumpeteriana fundamental de que a inspeção do que ocorre em níveis agregados é fruto de processos dinâmicos que emergem das decisões dos agentes. Apenas se aceita que exista como especificidade setorial uma forte articulação entre esses níveis de decisão no processo de evolução da agricultura e das cadeias agroindustriais. 
produtividade da agricultura em favor da visão geral de preservação do território e da tradição (Smedshaug, 2010).

As decisões macroeconômicas não são mero resultado da agregação individual de firmas em ambientes competitivos. Há a criação do consenso de que, semelhante ao fornecimento de energia, o suprimento alimentar está sempre sobre o abrigo de organizações de amplo alcance, como organismos internacionais (FAO, por exemplo), governos e uma gama de Organizações Não-Governamentais que atuam como grupos de pressão e de interesse (Aoki, 2007). O resultado deste processo condiciona fortemente o perfil das organizações produtivas e regulatórias do sistema agroindustrial e das organizações voltadas ao aprendizado continuado e à inovação. A natureza das cadeias agroindustriais coloca peso considerável nas organizações mundiais de controle fitossanitário e de biossegurança (FAO, 2001).

No nível mais específico, a natureza das atividades envolvendo as cadeias agroindustriais condiciona não só seus níveis de produtividade, mas o conjunto de alternativas viáveis da organização produtiva ${ }^{4}$. A teoria dos custos de transação encontra enorme apelo não só pela existência de fricções nas transações que ocorrem ao longo das cadeias produtivas - que se devem à assimetria de informações e à possibilidade de comportamentos oportunistas entre agentes - mas também pela própria dificuldade de mensurar o valor da contribuição de cada participante dos diferentes elos de produção até o consumidor final. Segundo Barzel (2004), a redução de erros de medida, via sistemas de padronização, minimiza custos de transação, diminuindo os custos de governança e as perdas de incentivo das integrações verticais e dos contratos de longo prazo. A construção de sistemas de padronização das mercadorias conecta o nível mais geral, apresentado acima, com a "firma agrícola", que está no centro do nível mais particular e microeconômico.

Segundo Teece (1980), a ideia de firma como lócus da gestão de recursos tangíveis e intangíveis permitiu avanço na teoria microeconômica. A firma agrícola continuaria a ser uma "caixa-preta" nos enfoques de base setorial? Allen e Lueck (1998) apresentam um modelo analítico com determinantes da escolha da forma de organização produtiva da agricultura ${ }^{5}$. Neste modelo, a tecnologia manifesta-se nos parâmetros que condicionam a articulação entre fases e etapas produtivas, dando ênfase à modularidade da produção agrícola, formulação inspirada em Alchian e Demsetz (1972). Os enfoques neoinstitucionalistas (especialmente a teoria dos contratos incompletos e a sociologia econômica) se aproximam e complementam as

(4) Não se trata de um jogo de palavras. O termo natureza refere-se aos condicionantes que interferem nas decisões produtivas dos agentes, introduzindo vários componentes aleatórios e abrindo espaço para vários tipos de assimetrias de informação. Esses componentes, apesar de sua importância, não são considerados, neste trabalho, como centrais para a discussão sobre inovação tecnológica. Ver Foster e Rosenzweig (1995).

(5) Allen e Lueck (1998) aplicam seu modelo explicativo ao processo de colheita mecânica de cereais no meio-oeste dos EUA. A especialização produtiva - chamada de monocultura pelos críticos da agricultura moderna - depende do custo de oportunidade de aumentar a produção e reduzir custos de transação. 
teorias de rede e de capacitações dinâmicas (Brosseau; Raynaud, 2008; Fligstein, 2008; Cowan; Jonard, 2003; Teece et al., 1997).

As atividades agrícolas movidas por processos de competição schumpeteriana, segundo Vieira Filho e Silveira (2011), aumentam os ganhos de produtividade e a competitividade, na maioria dos casos, pela redução dos custos de produção. Este hiato tecnológico mensurado pelo diferencial receita versus custos é explicado pelas distintas capacidades dos agricultores (em uma determinada localidade ou região) em combinar tecnologias e ganhar competitividade persistente e cumulativa, algo semelhante (não idêntico) ao que Sunkel e Infante (2009) definem como homogeneização progressiva da estrutura produtiva. Busca-se explicação para a heterogeneidade da agricultura entre e dentro dos países, que transcende as políticas de apoio à agricultura, baseadas em segurança alimentar, pressões inclusivas e preservação do espaço rural. A heterogeneidade produtiva (parcial e total dos fatores) verificada entre países e regiões pode ser explicada pela incorporação de inovações tecnológicas nos setores intensivos em recursos naturais.

Entretanto, avanços no crescimento da agricultura podem ocultar os problemas enfrentados por parte dos agricultores, que utiliza insumos tradicionais. Cabe ressaltar que a agricultura mal equipada, com um sistema de produção ineficiente, fica expulsa da competição cada vez mais intensa entre a agricultura moderna. Por um lado, embora haja aumento da produtividade, a revolução agrícola, a descoberta de novas terras agricultáveis e o desenvolvimento de uma agricultura mista, a qual emprega nível elevado de biomassa ${ }^{6}$, criam uma contradição do ponto de vista do equilíbrio socioeconômico, já que, por outro, verifica-se um maior empobrecimento com relativa exclusão na agricultura de agentes produtivos menos capacitados.

A brecha entre os sistemas agrícolas mais e menos produtivos tem sido acrescida em cerca de dez vezes nas últimas décadas (Vieira Filho; Santos; Fornazier, 2013). Tal descolamento está relacionado à heterogeneidade dos processos de aprendizagem, inovação e difusão dos novos conhecimentos. Em um ambiente cada vez mais competitivo, com a queda dos preços agrícolas, escassos investimentos em tecnologia dificultam regiões menos produtivas, de se inserirem no comércio internacional. Esta situação estaria agravada naqueles países que dependem da produção agrícola e que possuem tanto regiões modernas quanto atrasadas.

(6) A agricultura mista é aquela que engloba maior complexidade na produção de alimentos, fibras e energia, que são cada vez mais integrados à dinâmica do setor de serviços. Por exemplo, a produção de cana, depois de esmagada, pode ser, de um lado, transformada em açúcar, ou mesmo direcionada, de outro, à produção de etanol, por meio de processo fermentativo, bem como de bebidas alcoólicas. O bagaço, enquanto importante fonte de fibras, torna-se matéria-prima na produção de energia elétrica, por meio da queima e produção de vapor, ou transforma-se em etanol de segunda geração, por meio de hidrólise enzimática. Quanto maior a complexidade produtiva, maior é a inserção do setor de serviços ao longo do processo, e mais qualificado deve ser o agente produtivo. 
Podem-se tirar lições da relação entre desenvolvimento econômico, progresso técnico e agricultura. Os países desenvolvidos continuam defendendo a manutenção de políticas protecionistas - alguns sob o argumento de que existem pressões políticas internas; outros, como os europeus, na defesa do direito de preservar seu território, deslocando o eixo da discussão econômica para objetivos sociais mais amplos. Adicione-se a "crise dos preços agrícolas" pós-2002, que combina o choque do petróleo sobre o custo de produção da agricultura com a persistência da demanda de matérias-primas e alimentos pelos países emergentes, principalmente a China, mas também o Brasil, devido ao impacto de políticas redistributivas bem-sucedidas. Ademais, vale lembrar o papel da agricultura como fonte de energia renovável, combinada ao impacto (simbólico, inclusive) que a percepção do problema do aquecimento global acarretou sobre as visões de futuro da humanidade. Trata-se de um ambiente de imensa complexidade e, quer queiram ou não, de uma visão industrializante. A agricultura está no debate central.

Com a emergência do agronegócio, em 1970, rompeu-se a visão hegemônica de "funções da agricultura" como atividade progressivamente superada pela industrialização. $\mathrm{O}$ paradoxo estabelecido mostrava que havia um grande número de países (entre os quais se destaca o Brasil) com elevado índice de desenvolvimento humano que seriam considerados de "base agroindustrial", ou seja, países que foram capazes de conduzir processos de diversificação tendo o agronegócio como seu core. Ademais, desde 1980, a relação dos termos de troca no comércio internacional ${ }^{7}$ tornou-se favorável em vários países agroexportadores (vide Figura 1), o que desmistificou a argumentação de Prebisch (2000) de que a industrialização da América Latina não seria compatível com o desenvolvimento eficaz da produção primária.

Figura 1

Índice de termos de troca* da economia brasileira de 1950 a 2012.

(7) O termo de troca é aqui designado pela razão entre os índices de preço das exportações e das importações. 


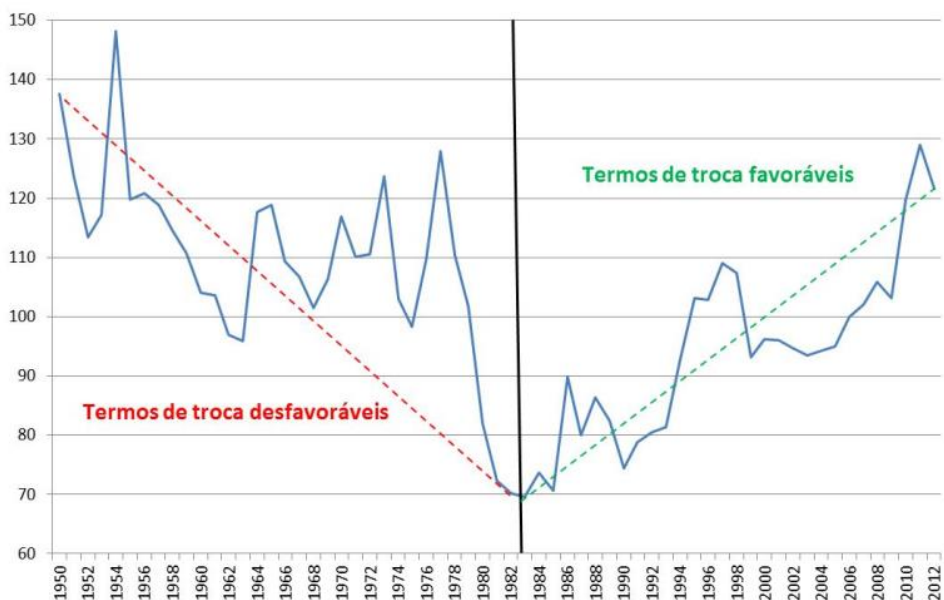

Obs $(*)$ : média $2006=100$.

Fonte: Ipeadata (2013).

Segundo Mattson e Koo (2006), o grupo de países em desenvolvimento que escapou da armadilha de pobreza teve um aumento de $300 \%$ no índice de produção agrícola contra apenas $68 \%$ de aumento dos países industrializados e $173 \%$ do total mundial. Os países em desenvolvimento (aqueles que se tornaram países industrializados e reduziram a porcentagem de pessoas vivendo em zonas rurais) passaram a contribuir de forma expressiva para o suprimento de matérias-primas, para alimentação e para setores industriais. Ocorreu nos países dinâmicos em agricultura algo semelhante ao que se passou com setores industriais intensivos em matérias-primas em outros países em desenvolvimento ${ }^{8}$. Conforme Mattson e Koo (2006), na década de 1980, o índice de produção agrícola per capita dos países em desenvolvimento que se industrializaram afastou-se dos indicadores do resto do mundo, sinalizando que alguns países, o Brasil inclusive, tornaram-se mercados de excedentes de alimentos ${ }^{9}$.

O padrão de industrialização das economias asiáticas, a ampliação do papel dos países emergentes (destaque para China e Índia) e a discussão sobre o possível distanciamento de alguns desses países em relação aos países desenvolvidos - que se situam no centro da crise pós-2008 - lançaram um novo debate sobre a exploração dos recursos naturais no desenvolvimento econômico, para além dos casos evidentes de "doença holandesa", como o da Venezuela.

(8) Por exemplo, plantas de intermediários para fertilizantes na Tunísia e Marrocos e plantas para produção de resinas termoplásticas "em cima dos poços de petróleo" na Arábia Saudita.

(9) Dados da FAO (2000, 2001) mostram que as Américas são fornecedoras líquidas de proteína vegetal e animal para o mundo. O continente asiático é responsável pela quase totalidade da produção de arroz e de seu consumo. A produção de fontes energéticas, como milho e trigo, é melhor distribuída. O continente europeu, que há anos era importante fonte de alimentos para a humanidade, só tem participação relevante no trigo, em parte como resultado de suas políticas protecionistas e de defesa da noção de território. 
Seguindo este raciocínio, a ocorrência de um "boom" de preços de commodities causaria uma mudança nos padrões setoriais do país, gerando um choque permanente cuja consequência fosse a desindustrialização, que levaria à queda na produtividade média do trabalho do setor manufatureiro. Em resumo, nas economias baseadas em recursos naturais, o aumento da lucratividade neste segmento da economia poderia desencadear um processo danoso que deveria ser evitado por políticas macroeconômicas (ver Gylfason; Zoega, 2006).

Mais que apontar o recurso às políticas compensatórias macroeconômicas, Perez (2010) propõe um conjunto de estratégias para os países em desenvolvimento apoiados na exploração de recursos naturais. Além disso, busca-se não generalizar a ideia de que a exploração de atividades primárias traria grau reduzido de impactos de encadeamento na economia - caso típico dos enclaves mineradores - e que estaria intrinsecamente ligada ao baixo conteúdo tecnológico e, por consequência, à baixa produtividade.

$\mathrm{O}$ "choque cambial agrícola" seria baseado em frágil evidência empírica e em limitação conceitual. A ideia de que uma alta de preços com consequente valorização cambial causa a "resposta" de uma multiplicidade de pequenos agricultores dispersos geograficamente (ineficientes do ponto de vista alocativo e tecnológico) não resiste na literatura sobre cadeias agroindustriais dos países que lideram a pauta agroexportadora.

Tomando o caso brasileiro, segundo Buainain, Souza Filho e Silveira (2002), a participação dos pequenos agricultores no abastecimento tem relação com agricultores integrados às cadeias produtivas, que possuem dinâmicas de formação de preços distintas da "agricultura competitiva". Parte da produção de grãos em países exportadores dirige-se para o mercado interno, o que viabiliza a competitividade a jusante, de produtos alimentares com maior valor adicionado. ${ }^{10}$

A despeito dos elevados custos sociais do modelo agrário, principalmente no período militar (Veiga, 1992), o processo de constituição de um agronegócio competitivo permitiu o país aproveitar do crescimento chinês e asiático, proporcionando saldos comerciais favoráveis com menor restrição externa ${ }^{11}$. A história da agricultura na França reflete as políticas públicas visando a transformação do espaço das atividades agrícolas em território de pluriatividade. Na Argentina, a

(10) Como no caso dos frangos resfriados e congelados, em que o Brasil é o maior exportador mundial, conforme destacado por Murakami (2010).

(11) A ligação entre política macroeconômica, a apreciação cambial decorrente da entrada de dólares e o modelo agroexportador não leva em conta um elemento fundamental na história recente da agricultura brasileira: a existência de um grave problema alimentar no final da década de setenta, como apontou Mello (1983), superado pelos resultados decorrentes de profundas mudanças institucionais no sistema agrícola, das políticas de financiamento em Ciência, Tecnologia e Inovação (C\&T\&I) iniciadas no início da década de setenta (Buainain et al., 2002). 
elite ruralista construiu uma dinâmica agroindustrializante, pondo em cheque velhas políticas de taxação das exportações agrícolas e resultando em novas questões, como dependência tecnológica e reorganização do espaço rural (Bisang; Varela, 2008).

Esses processos históricos diferenciados permitem questionar um esquema desenvolvimentista que separa agricultura e indústria e, pior ainda, que associa os resultados de exportação da agricultura unicamente ao impacto de políticas lideradas por elites agrárias e conservadoras. Existem países industrializados, com elevada produtividade do trabalho industrial, que são grandes exportadores agrícolas e que utilizam a indústria como elemento de potencialização de seus recursos naturais (World Bank, 2008).

Esses países caracterizam-se por elevado grau de urbanização, participação diversificada da agricultura no PIB e pobreza rural abaixo de $40 \%$. Dos EUA a Austrália, passando por Brasil, Canadá e Argentina, tem-se um grupo privilegiado de países exportadores de bens agrícolas com distintas dinâmicas macroeconômicas, mas com certa convergência no padrão tecnológico que transfere vantagens competitivas às cadeias agroexportadoras ${ }^{12}$.

A tecnologia parece cumprir um papel privilegiado, ainda que as visões sobre desenvolvimento tecnológico sejam marcadas por ambigüidade e conflitos. A trajetória tecnológica que marca o desenvolvimento de um moderno setor agrícola é determinada por sistemas complexos de inovação. Procurou-se mostrar aqui que vários países e regiões foram capazes de conduzir um processo de desenvolvimento econômico com base agroindustrial em seu núcleo de crescimento.

\section{Trajetória Tecnológica Ampliada (TTA) da agricultura: uma construção histórica}

O capital tecnológico é um dos fatores essenciais ao incremento da produtividade; sua acumulação depende das estratégias individuais de investimento dos agentes e da capacidade, em âmbito regional, de adaptar conhecimento e tecnologia. Nesse sentido, existe uma complexa relação entre os agentes produtivos e as várias instituições (públicas e privadas) ao longo da cadeia produtiva regional (Vieira Filho et al., 2005).

Por não compreender o funcionamento da moderna agricultura ou por definir o caso agrícola como setor retardatário, alguns estudos insistem na dinâmica tecnológica exógena ao setor produtivo. De maneira inversa, a agricultura é análoga ao enfoque de filières industriais. A adoção tecnológica, baseada no conhecimento prévio acumulado, é interpretada como um mecanismo de experimentação que, se

(12) O fato de os EUA subsidiarem seus agricultores como parte de um arranjo político e, na última década, como parte da política energética, confirma o raciocínio de que a interação entre potencialidades de clima e solo e o esforço inovativo constituem condição de competitividade. 
bem sucedido, promove a difusão da técnica. Tal difusão interessa ao segmento fornecedor, seja por aumento das vendas ou crescimento do lucro. A interdependência da produção agrícola e da cadeia produtiva se define pela troca de informações, no intuito de adequar as novas tecnologias às condições produtivas regionais específicas. O processo de adoção tecnológica depende, por sua vez, do estoque de conhecimento de cada agricultor. Como mostrado por Esposti (2002, p. 694),

Firstly, innovations in agriculture are often site-specific to some extent and transfer can be constrained by multiple factors: adaptation to climate and soil, particular pest problems, specific local crops or products, and so on. Secondly, however, many sources and channels of innovation can create new technological opportunities for the farm production also in site-specific contexts whenever these opportunities are adequately adapted.

A organização da atividade agrícola é definida em sentido amplo, passando pelo setor fornecedor de insumos, pela unidade produtiva e pela distribuição. $O$ processo de inovação na agricultura é constituído por complexos arranjos produtivos, interligados entre si, mediado por instituições promotoras do conhecimento, como centros de pesquisa, universidades, empresas de extensão rural e órgãos reguladores do Estado. Conforme Nelson e Winter (1977, p. 47-48),

(...) in agriculture, there is considerable public subsidization of research done by predominantly non-profit institutions (largely universities) and a subsidized federal-state extension service for the dissemination of information regarding new technological developments to farmers, interacting with the network of private farms, and industries that produce and sell farm equipment, fertilizers, etc.

A relação da produção agrícola com o uso de insumos não se dá por meio da dependência tecnológica, mas fundamentalmente no que tange à complementaridade setorial e à coevolução da produção agrícola e do desenvolvimento de novas tecnologias. Os estudos empíricos de Malerba e Orsenigo (1996) e Breschi, Malerba e Orsenigo (2000) registraram que a estrutura institucional para o desenvolvimento da inovação é muito complexa dentro de um setor econômico (e a agricultura não foge à regra) e varia no conjunto dos demais setores, sendo heterogêneo entre os mesmos. O regime tecnológico agrícola define condições específicas de oportunidade, apropriação, cumulatividade e propriedades da natureza do conhecimento.

As principais transformações da TTA agrícola tiveram início há cerca de 200 anos. Entretanto, somente em meados do século passado estas transformações alteraram significativamente a produtividade agrícola ${ }^{13}$. Até 1900 , a produção

(13) Cf. Mowery e Rosenberg (2005). 
agrícola era organizada de forma manual e com técnicas rudimentares de cultivo. Em 1920, técnicas mais refinadas foram introduzidas. Na década de 1940, as indústrias químicas e de veículos automotivos beneficiaram-se dos avanços científicos e tecnológicos, seja em torno do motor a combustão interna ou no crescimento da indústria petroquímica (substituição da matriz energética dos produtos químicos orgânicos, cuja matéria-prima era o carvão, pelo petróleo e gás natural).

Em meados da década de 1950, tem-se o aparecimento da indústria farmacêutica, setor diferenciado da indústria química, apoiado pelo desenvolvimento dos conhecimentos de base. Em seguida, surgiu a biotecnologia que, na área agrícola, propiciou o uso de sementes híbridas e melhoradas. O crescimento da moderna indústria de biotecnologia se iniciou em 1970 com a biologia molecular e se firmou, desde 1990, com a manipulação genética de plantas e organismos vivos.

Define-se a TTA como sendo o conjunto de várias trajetórias tecnológicas (associadas aos clusters de inovações no tempo) que se interagem em um processo coevolutivo (Vieira Filho, 2012). O avanço tecnológico, em uma dada direção, impacta as oportunidades dos demais insumos tecnológicos em suas respectivas trajetórias e caminhos. Pela Figura 2, o eixo vertical esquerdo mostra o aumento da produtividade, variando de baixo a elevado. $\mathrm{O}$ eixo horizontal determina o grau de modernização agrícola, conteúdo tecnológico ou combinação eficiente de insumos, que varia de conteúdo restrito (agricultura tradicional) ao intenso (produtor moderno $)^{14}$. Finalmente, no eixo vertical à direita, situam-se os principais aglomerados de inovações tecnológicas na agricultura, as revoluções químicas, mecânicas e biotecnológicas. Para um dado conteúdo tecnológico $(x)$, dentro da área de variabilidade, é possível alcançar diferentes níveis de produtividade, variando de $y_{1}$ a $y_{2}$. O estoque de conhecimento de cada produtor determina o desempenho produtivo. Quanto mais próxima de $y_{2}$ a produtividade, o estoque de conhecimento é máximo. Se a produtividade estiver próxima de $y_{1}$, o agricultor possui baixa absorção de conhecimento. O investimento produtivo possui duas funções. A primeira visa aumentar o grau de conteúdo tecnológico, o que expande o segmento de reta que representa os diferentes níveis de produtividade. A segunda se associa ao aumento da capacidade de absorção de conhecimento externo. Ao ampliar o conteúdo tecnológico e a capacidade de absorção, via gasto em investimento, o agricultor estaria habilitado a alcançar maior produtividade dentre todas as possíveis.

Figura 2

Trajetória tecnológica ampliada da agricultura

(14) Quanto maior for a intensidade do conteúdo tecnológico, maior será a capacidade do agricultor de inovar. 


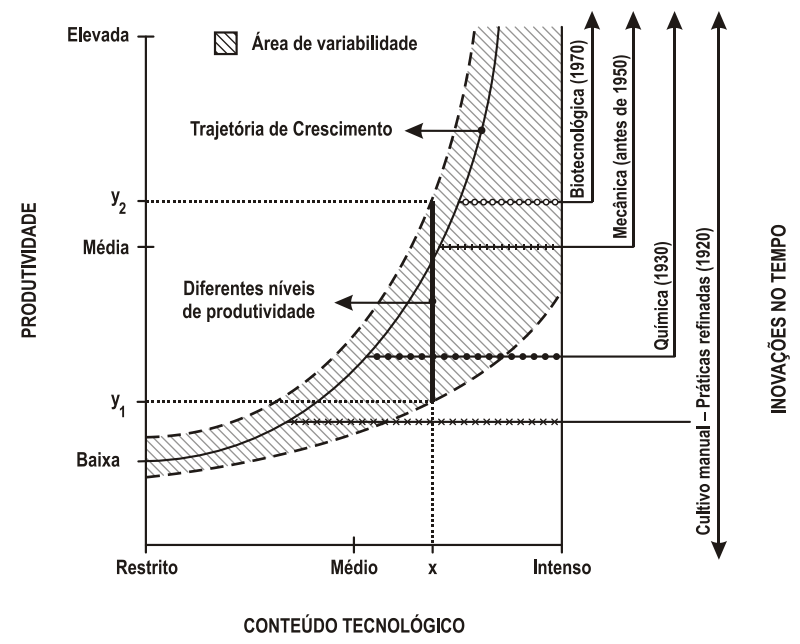

Fonte: Vieira Filho (2009)

A revolução tecnológica isolada do processo de aprendizado não garante o aumento da produção nem o uso eficiente do conteúdo tecnológico. A seleção de variedades de sementes sensíveis à aplicação de fertilizantes e de defensivos é um exemplo de interdependência das trajetórias inovativas. A indústria química, com a introdução constante de inovações incrementais, propiciou redução do custo da fertilização do solo e da prevenção contra pragas e doenças. A adoção de sementes de elevado rendimento estava vinculada aos custos decrescentes dos fertilizantes e defensivos. Ao deslocar os preços relativos dos insumos, as inovações da indústria química definiram caminhos de dependência e trajetórias do desenvolvimento biotecnológico. Outro exemplo foi o desenvolvimento de variedades passíveis de colheita mecânica, como o tomate de casca mais resistente e amadurecimento sincronizado. O progresso tecnológico depende de avanços simultâneos, tanto em inovações biológicas quanto em mecânicas, já que esta última se adapta às características da primeira. Neste caso, o esforço de pesquisa biológica foi conjunto às pesquisas de engenharia mecânica ${ }^{15}$.

O desenvolvimento econômico é entendido em termos de dotações favoráveis de recursos naturais. O petróleo não seria explorado se não houvesse tecnologia de extração mineral. O forno elétrico converteu a bauxita em um metal de alto valor econômico e, no mesmo período, transformou automóveis sucateados em fonte de aço a baixo custo. Na química avançada, foi possível fixar nitrogênio atmosférico em fertilizante agrícola. Na agricultura, parte do crescimento deveu-se ao uso de insumos químicos, incluindo tanto os fertilizantes sintéticos à base de

(15) Cf. Mowery e Rosenberg (2005); Silveira, Borges e Fonseca (2007); Achilladelis, Schwarzkopf e Cines (1990) e Hayami e Ruttan (1988). 
nitrogênio quanto os herbicidas e inseticidas. O automóvel mudou a organização da vida urbana e o trator dinamizou o trabalho no campo.

Enfim, conforme Mowery e Rosenberg (2005), os recursos naturais adquirem valor econômico a partir do desenvolvimento de capacidades tecnológicas, que são construídas por instituições e pela acumulação do conhecimento. Tais autores mostraram que o crescimento econômico americano nos séculos XIX e XX se deu em torno, basicamente, de alguns grandes setores econômicos: do metalmecânico, juntamente com a evolução da indústria automobilística e aeronáutica, dos produtos químicos, do segmento de energia elétrica e da eletrônica, a partir de $1960^{16}$.

Pavitt (1984) e Bell e Pavitt (1993) destacaram que os padrões de inovação variam em diferentes mercados e setores industriais. Tais autores procuraram definir uma taxonomia explicativa das trajetórias tecnológicas de cada segmento. Quanto à classificação dos negócios das firmas, estabeleceram-se cinco tipos: (i) dominado pelos fornecedores - indústria têxtil e agricultura; (ii) intensivo em escala - setor siderúrgico, indústria de bens duráveis, segmento automobilístico e engenharia e construção civil; (iii) intensivo em informação - setor bancário e financeiro, mercado editorial e publicitário, turismo; (iv) baseado em ciência - segmento químico e indústria eletrônica; e (v) fornecedores especializados - indústrias de bens de capital, de instrumentos e de software. Entretanto, a especificação da agricultura como um setor dominado pelos fornecedores não se encaixa na complexidade das transformações ocorridas na indústria química, mecânica e biotecnológica ${ }^{17}$. Estes autores, op. cit., padronizam as trajetórias tecnológicas setoriais, enfatizando a interpretação estática sem considerar a questão dinâmica, essencial na agricultura, já que a tecnologia é gerada em uma gama de setores inter-relacionados à firma agrícola.

A Tabela 1 apresenta indicadores do progresso técnico na agricultura ${ }^{18}$. Entre 1961 a 2012, o número de máquinas cresceu quase 3 vezes, sendo que as

(16) Para um estudo dos setores metal-mecânico, químico, de energia elétrica e eletrônico, vide Mowery; Rosenberg (2005). Quanto à indústria química em separado, busque Achilladelis, Schwarzkopf e Cines (1990). Em Dosi (1984), encontra-se uma completa análise do segmento de semicondutores. Em relação à agricultura, confira Sahal $(1981,1985)$. No que se refere a um estudo revisitado da biotecnologia, tem-se Silveira, Borges e Fonseca (2007).

(17) Para um estudo mais detalhado das transformações ocorridas na agricultura nos últimos 50 anos, confira o relatório da FAO (2000) acerca da situação mundial de alimentação e da agricultura. Ver também Smedshaug (2010).

(18) Normalmente, a mensuração das transformações tecnológicas na agricultura é calculada em termos da produtividade total dos fatores (PTF), sendo um índice que subtrai a taxa de crescimento agregado dos insumos do crescimento do produto. O crescimento da PTF capta o crescimento do produto que é devido a uma combinação eficiente de insumos, seja pelo uso adequado de informação ou pelo nível de atualização tecnológica (ver Sadoulet; De Janvry, 1995). Mudanças da produtividade resultam de diferenças na eficiência, na variação da escala produtiva 
colheitadeiras duplicaram no período. A área equipada para irrigação quase dobrou. O consumo de fertilizantes aumentou em cerca de 6 vezes. Quanto ao uso de pesticidas, ao final do período, havia maior variedade de ingredientes ativos. A produtividade dos cereais $(\mathrm{kg} / \mathrm{ha}$ ) mais que dobrou no período. Quando comparada à produtividade por regiões, nota-se que os países emergentes ficam próximos de alcançar a produtividade dos países desenvolvidos. Observa-se a aceleração da taxa de crescimento - cereais principalmente - no segundo período (de 1990 a 2012) comparada ao primeiro (1961 a 1990) para países como Brasil e Argentina, enquanto que o mesmo indicador sofre uma desaceleração para regiões mais desenvolvidas como Estados Unidos e Europa nos respectivos períodos. Situação similar acontece com a produção de carne. Em termos da produtividade de carne de frango, tal indicador foi muito maior em países como Brasil e Argentina do que o contrário.

\section{Tabela 1}

Indicadores do progresso técnico da agricultura por países e regiões selecionadas entre 1961 a 2012 
Competências organizacionais, trajetória tecnológica e aprendizado local na agricultura...

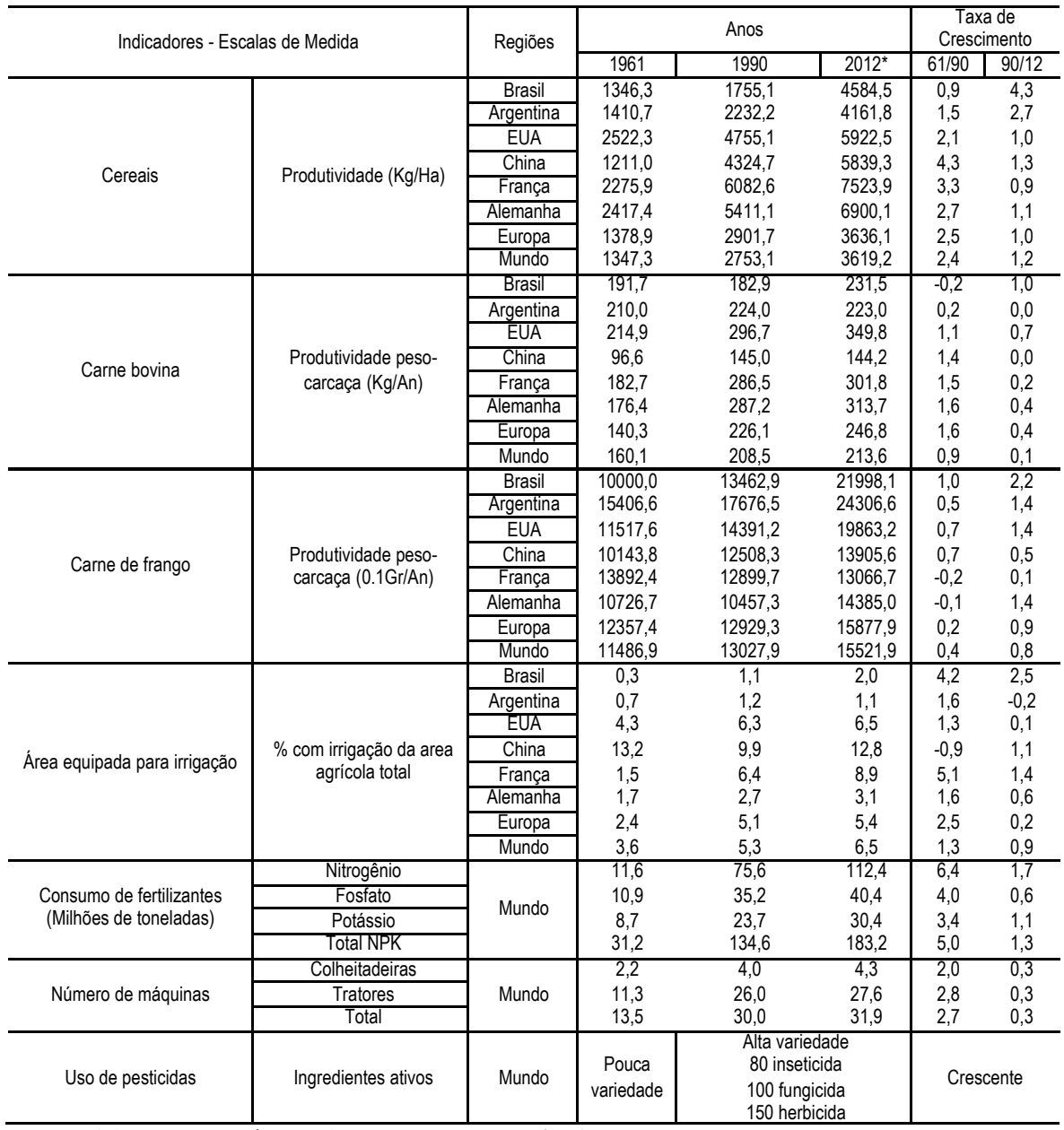

Fonte: Elaboração própria com base em FAOSTAT (vários anos)

Obs (*): 2012 para a maioria das variáveis estudadas, ou estatística mais recente disponibilizada.

Conforme FAO (2000), de 1950 até 2000, o rendimento médio do trigo nos Estados Unidos passou de 1100 para mais de $2600 \mathrm{~kg} / \mathrm{ha}$, sendo que o uso de fertilizantes minerais foi de 20 a $120 \mathrm{~kg} / \mathrm{ha}$ de área plantada. Na França, a produtividade do trigo registrou passagem de 1800 a $7100 \mathrm{~kg} / \mathrm{ha}$ e o uso de fertilizantes sofreu acréscimo de mais de 5 vezes. Em 2000, nas terras mais férteis da Europa, os rendimentos do trigo e do milho ultrapassam $10000 \mathrm{~kg} / \mathrm{ha}$, com dosagem de fertilização por hectare da ordem de $200 \mathrm{~kg}$ de nitrogênio, $50 \mathrm{~kg}$ de fosfato e $50 \mathrm{~kg}$ de potássio. É óbvio que, para este crescimento, foi preciso selecionar variedades de sementes mais adaptadas à absorção de nutrientes.

Como demonstra Nelson e Winter (1982) e Metcalfe (2002), a busca por estratégias inovativas se insere em um ambiente de competição, sendo o mercado 
um mecanismo de seleção ${ }^{19}$. A difusão de uma tecnologia é acompanhada de várias transformações importantes no seu projeto. Uma ampla variedade de inovações consiste em superar, pelo aprendizado, as limitações que resultam de um processo de dimensionamento da tecnologia em questão. A mudança tecnológica é caracterizada como um processo de aprendizagem pela escala (learning by scaling) (Sahal, 1981, 1985).

Parte do crescimento da produtividade agrícola foi realizada por melhoramentos da eficiência dos combustíveis (aumento da potência para um dado peso) e por maior velocidade das maquinarias e tratores. $\mathrm{O}$ trator foi introduzido no intuito de substituir a força animal pela mecânica. $O$ propósito original foi se alterando, ficando evidente que o projeto do trator foi largamente moldado pelo sistema de produção agrícola. Em resumo, mudanças na escala tecnológica de operação constituem características indutoras da inovação.

Pela Figura 3, observa-se que o desempenho tecnológico da mecanização ao longo do tempo é dependente do tamanho e da estrutura das fazendas. A mecanização foi dividida em cinco estágios, tendo o conteúdo tecnológico aumentado na escala de I a V. Nota-se que cada etapa foi traduzida pelo crescimento da superfície cultivada (ou do número de animais por trabalhador nos estágios inferiores) e pelo aumento da produtividade, que se associa, paralelamente, aos avanços químicos e biológicos.

A mecanização foi desenvolvida precocemente em alguns cultivos, antes mesmo do primeiro estágio se iniciar. Os cultivos de grande porte (cereais e grãos) foram primeiramente beneficiados, sendo condutores do movimento expansivo recente. A produção em grande escala definiu trajetórias tecnológicas na indústria de máquinas e equipamentos. A mecanização foi seguida de maior padronização da colheita, principalmente na produção de alimentos pesados, volumosos e de difícil transporte. Posteriormente, ganhou-se espaço para o uso mecânico no trato do gado leiteiro, na pecuária, na colheita de forragens, no setor sucroalcooleiro e nos cultivos de legumes e frutas.

O primeiro estágio (Mecanização I) iniciou-se pouco antes de 1950, sendo as propriedades agrícolas maiores de 15 ha por trabalhador com o uso de tratores menos potentes (10 a 30 cavalos). As etapas subsequentes (Mecanizações II, III e IV) surgiram entre 1960 a 1980. Além do predomínio de superfícies mais extensas por trabalhador (50, 80 e 100 ha), teve-se a adoção de máquinas e tratores com potência crescente (variando, respectivamente, entre 30 a 50,50 a 75 e 75 a 120 cavalos) e de uso diversificado, seja no manejo do solo, no plantio ou na colheita. Por fim, o quinto estágio (Mecanização V) se deu em 1990 com força mecânica acima de 120 cavalos e áreas plantadas superiores a 200 ha por trabalhador.

(19) Esta análise, para o caso agrícola, é corroborada por Possas, Salles-Filho e Silveira (1996), Vieira Filho, Campos e Ferreira (2005), Vieira Filho e Silveira (2011) e Vieira Filho (2012). 
Figura 3

Etapas do desenvolvimento dos equipamentos e da mecanização na produção de cereais (em quintais)*

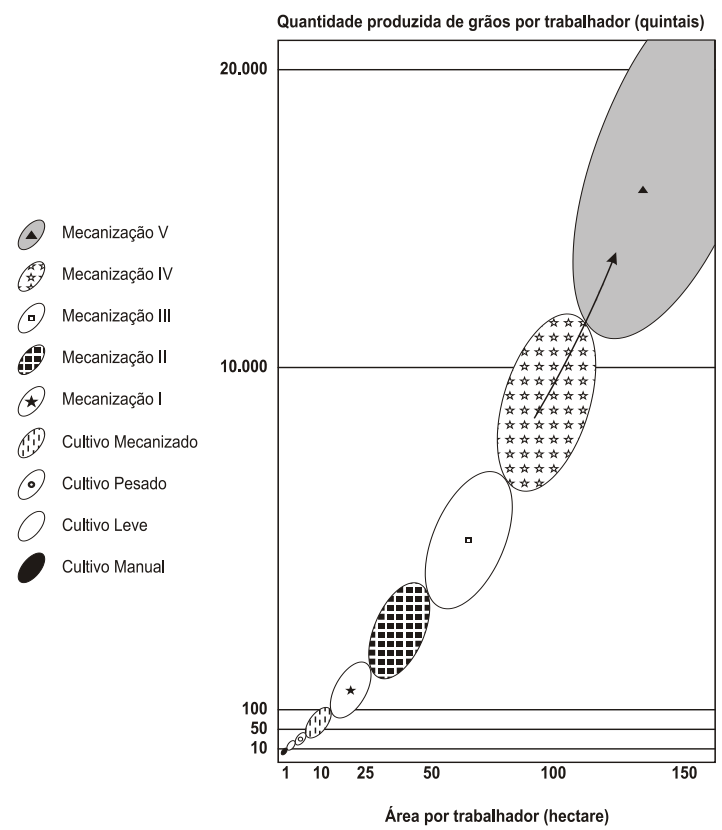

Obs: (*) 1 quintal $\cong 45$ a 50 quilogramas.

Fonte: Adaptado de FAO (2000, p. 178).

A tecnologia dos tratores foi definida de forma gradual. Os avanços foram originados na solução de problemas específicos da produção, do projeto e do uso das máquinas, dependendo da experiência e da acumulação de conhecimento. Os pontos de estrangulamentos de conhecimento permitem identificar novas avenidas do progresso técnico ${ }^{20}$. Segundo Sahal (1985, p. 71),

(...) the process of technological development within any given field leads to the formation of certain pattern of design. The pattern in turn guides the subsequent steps in the process of technological development. Thus innovations generally depend upon bit-by-bit modification of an essentially invariant pattern of design. This basic design is in the nature of a technological guidepost charting the course of innovative activity. (...) technical advances (...) are expected to occur in a systematic manner on what may be called innovation avenues that designate various distinct pathways of evolution.

(20) Em Sahal (1985), além dos tratores e máquinas agrícolas, são estudados dois outros casos setoriais (a indústria da aeronáutica e a de informática e computadores). O arcabouço de análise discutido nestes três casos investiga os determinantes da inovação tecnológica ligados às questões da especialização via escala produtiva e do aprendizado ao longo do tempo. 
Como sugerido por Possas, Salles-Filho e Silveira (1996, p. 939), “(...) the interpretation of technological trajectories and of the formation of a technological regime in agriculture should be made on the basis of the notion of problem areas". $\mathrm{O}$ conhecimento é subdividido em partes codificadas e outras tácitas. O aspecto coletivo do conhecimento inclui o conhecimento codificado, que pode ser facilmente compartilhado com outras habilidades técnicas e resolver problemas mais gerais de engenharia.

A inovação tecnológica, mesmo em setores intensivos no uso de recursos naturais, é capaz de promover rendimentos marginais crescentes ${ }^{21}$ e vantagens comparativas dinâmicas. O raciocínio ricardiano da renda da terra estática não se aplica, já que a construção de tais rendas se faz junto ao aprendizado e às mudanças tecnológicas no tempo. Como visto por Dosi (1988, p. 1138), “(...) Mechanization, chemical fertilizers and pesticides, new breeds of plants and animals and improved techniques of mineral extraction and purification prevented scarcity from becoming the dominant functional feature of these activities". Assim, o surgimento de novos paradigmas tecnológicos em algumas áreas de concentração do conhecimento, que interagem direta ou indiretamente com os antigos modelos tecnológicos, geralmente impede, em um processo de busca por inovações, o estabelecimento de retornos decrescentes. Portanto, além de focar a questão dos retornos crescentes, a concepção da TTA fornece elementos - teórico e analítico - para a compreensão da dinâmica agrícola.

\section{Aprendizado localizado}

O processo de aprendizado condiciona a TTA, em um determinado paradigma científico, potencializando as oportunidades tecnológicas, e introduz o fator dinâmico do progresso técnico. A transferência tecnológica para os agricultores requer investimentos ligados às capacidades gerenciais, que conferem maior habilidade em explorar conhecimentos externos (Evenson; Kisley, 1973; Cohen; Levinthal, 1989).

Analogamente ao modelo Chiaromonte e Dosi (1992), dado que as indústrias a montante da unidade produtiva têm trajetórias tecnológicas bem definidas e que, simultaneamente, geram insumos (ou inovações radicais) que alteram os coeficientes da produtividade agrícola, muitas concepções tratam as transformações da agricultura como um resultado do processo de difusão técnica. Logo, para aumentar

(21) No intuito de abordar os rendimentos crescentes da adoção, Foray (1989) especifica um modelo de competição tecnológica em que se trata o aprendizado pela experiência, as externalidades de rede, as economias de escala, a difusão crescente de informações e as complementaridades tecnológicas. No que se refere à organização da firma em termos de economias de escala e de escopo, Teece (1980) discute amplamente as habilidades gerenciais na busca por aprendizado e inovações. 
a produtividade da agricultura, bastaria melhorar as condições da difusão tecnológica. Esta visão é insuficiente para a compreensão da complexidade agrícola.

De acordo com Klevorick et al. (1995, p. 186), “(...) $R \& D$ intensity in a industry is largely determined by two key variables: technological opportunities and the ability to appropriate returns from new developments". A primeira determina a produtividade da pesquisa, enquanto que a segunda estabelece a fração dos retornos da pesquisa que o inovador é capaz de reter. Na agricultura, os investimentos em pesquisa e desenvolvimento são essenciais na construção desta habilidade. As oportunidades tecnológicas dependem dos avanços científico e técnico, da tecnologia advinda de outras indústrias e do feedback do progresso técnico no próprio segmento agrícola. "Advances in production process technology and equipment, which are often the result of work done by upstream suppliers, also can expand a downstream industry's opportunities to improve product attributes and designs" (Ibidem, p. 191).

O grau de eficiência tecnológica se diferencia entre os produtores pela variabilidade da capacidade de absorção de conhecimento externo (fator endógeno), o que determina o estoque de conhecimento, e pela diversidade climática e geográfica da agricultura (variável exógena), já que uma mesma tecnologia terá retorno produtivo diferenciado em função das especificidades locais. Assim, os recursos produtivos (seja do lado gerencial ou das questões ambientais) estão distribuídos geograficamente de forma desigual. A distribuição desigual destes recursos explica em parte o crescimento diferenciado de distintas regiões ${ }^{22}$. Conforme Esposti (2002, p. 696) ${ }^{23}$,

The absorptive capacity actually depends on own research effort whenever knowledge and innovations are 'complex'. 'Complex innovations' means that they require learning and adaptations to become effective in the specific context (the recipient firm).

Dependendo do Sistema Nacional de Inovação, a adoção tecnológica tem por objetivo incorporar o conteúdo tecnológico dos insumos, os quais são produzidos em outro contexto regional. O objetivo da introdução de conhecimentos externos é captar o conteúdo embarcado dos insumos. Algumas regiões (ou países), como

(22) Para um estudo que mostra o distanciamento do desenvolvimento agrícola africano em relação ao resto do mundo, ver Johnson e Evenson (2000). Alguns países em desenvolvimento não possuem instituições que promovam a inovação doméstica ou a transferência de tecnologia estrangeira às condições locais. Ao mesmo tempo, o baixo incentivo em inovação e os escassos investimentos em instrução técnica dos produtores são responsáveis por um baixo crescimento produtivo nas regiões mais pobres.

(23) Embora o estudo deste autor aborde a capacidade de absorção do Sistema Nacional de Inovação Agrícola, enfoque análogo pode ser adotado na ótica do agricultor em captar os efeitos de transbordamento. Os termos "spill-in", "spill-out" e "spillover" são diferentes formas de denominação da transferência tecnológica. Do ponto de vista do setor receptivo, o programa de pesquisa (ou investimentos) gera um "spill-in". No outro extremo, considera "spill-out" (ou "spillover"), se o setor provedor de novos conhecimentos for o foco. 
mostrado por Esposti (2002), agem de forma oportunista (como free rider - o carona) no intuito de absorver o conteúdo tecnológico embarcado, sem ao menos efetuar investimentos necessários em capacidade de aprendizado e adaptação tecnológica. Mudanças tecnológicas estão relacionadas à capacidade de assimilar conhecimento externo, que decodifica as instruções atreladas às inovações (ou insumos modernos). São os elementos tácitos que podem distinguir o desempenho produtivo privado, o que altera a performance da técnica de produção, normalmente de domínio público.

O contexto institucional, no qual a tecnologia é introduzida, pode influenciar o resultado das técnicas produtivas. Se a tecnologia possui elementos tácitos, os ganhos do aprendizado e da inovação são conjuntamente envolvidos. Segundo Bardhan e Udry (1999), o investimento local de aprendizado desenvolve o conhecimento tácito, seja pela aplicação (learning by doing) ou mesmo pelas externalidades de rede (learning from others). No primeiro caso, a experimentação se liga a retornos incertos de produtividade. Já no segundo, o investimento dos produtores vizinhos cria transbordamento de informações, propiciando externalidades de aprendizado.

Foster e Rosenzweig (1995) discutem a adoção e a produtividade de novas variedades de sementes. Os avanços tecnológicos estariam associados ao aprendizado pelo uso e aos efeitos de transbordamento do conhecimento local (learning spillovers). A produtividade da nova semente aumenta no tempo via acumulação de conhecimento. Enquanto a falta de conhecimento em gerenciar novas variedades cria barreira à adoção, a experiência dos vizinhos contribui para melhorar o gerenciamento das novas variedades, o que conduz a um aumento da produtividade líquida. As barreiras diminuem com o aumento da experiência própria e dos vizinhos nos primeiros anos de adoção. Assim, agricultores com vizinhos experientes são mais lucrativos do que o contrário.

A ocupação do Cerrado brasileiro, desde 1970, é um exemplo de como as especificidades locais se moldam no aprendizado no tempo. Podem-se identificar trajetórias tecnológicas bem definidas no desenvolvimento agrícola, não sendo apenas um tipo específico de inovação, mas um conjunto de inovações graduais em várias áreas do conhecimento (biológicas, químicas e mecânicas) associadas à dimensão da escala das fazendas. No melhoramento genético, foram realizadas diversas pesquisas no intuito de adaptar mudas e sementes resistentes ao clima da região (seco e quente $)^{24}$. O desenvolvimento de plantas adaptadas propiciou a expansão da fronteira agrícola, sendo a soja o experimento. Simultaneamente, a mecanização foi intensificada, devido ao tipo de terreno mais plano, o que favorecia o uso de máquinas e tratores.

(24) Os estudos de melhoramento genético se iniciaram na primeira metade do século passado e ampliaram os conhecimentos básicos. Nas décadas de 1970 e 1980, seguiu-se um maior esforço para aplicação do conhecimento gerado ao longo dos anos anteriores. 
Porém, a utilização das máquinas não era intensa, já que a escala produtiva e a produtividade eram pequenas, devido à baixa qualidade do solo. No início de 1980, a inoculação na semente da soja por bactérias que captam o nitrogênio do solo permitiu o crescimento da produção com menor uso de fertilizantes, contribuindo para aumento da escala produtiva com maior produtividade por área plantada. Assim, o uso de máquinas mais potentes e de grande porte, bem como a regulagem das colheitadeiras, evitando-se o desperdício de grãos, contribuiu para o aumento da produção de soja, em uma região até então marginalizada do mercado.

A direção e o grau da mudança tecnológica são moldados pela existência de recursos naturais essenciais ao desenvolvimento. Embora a terra fosse um recurso abundante no Cerrado brasileiro, a incorporação da nova fronteira agrícola não seria possível na ausência das várias tecnologias desenvolvidas e da capacidade de aprendizado localizado dos agricultores. Os recursos naturais não possuem intrinsecamente valor econômico. Para que os recursos sejam extraídos e explorados, o conhecimento tecnológico é essencial.

O plantio direto e o cultivo de transgênicos são também exemplos que ilustram a importância do aprendizado localizado e da TTA. O uso do plantio direto é considerado fundamental para preparo do solo no Brasil. Ao contrário das técnicas tradicionais de aração e gradação que ainda perduram em muitas regiões, o ganho obtido tem relação direta com a capacidade de aprendizado do agricultor e o desenvolvimento específico de máquinas e equipamentos voltados a este manejo. A difusão do plantio direto e conhecimento mínimo desta técnica justificaram o desenvolvimento industrial dos equipamentos por algumas empresas (como Semeato, Tatu, Marchezan, Baldin).

Trata-se de uma clara inovação em processo, cujo resultado, em competitividade, na forma de melhor conservação dos recursos naturais, que depende do conhecimento do agricultor e das especificidades da propriedade agrícola. Originalmente desenvolvido nos EUA, em 1972, o plantio direto desenvolveu-se no Brasil como vantagem competitiva, que permitiu aos agricultores reduzirem os efeitos negativos do clima tropical sobre o solo, acentuado pelas técnicas trazidas da Europa.

No Brasil, o plantio direto se deveu ao trabalho de agricultores holandeses, que se estabeleceram no Paraná, região de solo originalmente inadequado ao cultivo de grãos. Estes agricultores, seguindo o conceito de guidepost e tendo um claro problema a resolver (erosão, compactação do solo e exposição desnecessária do terreno às intempéries no preparo do solo), conceberam processos, cuja ideia básica pretendia revirar ao mínimo o solo ${ }^{25}$. Tais agricultores estenderam as técnicas de plantio, desenvolvendo novas plantadeiras. Os mesmos aproveitaram a existência de

(25) Daí o nome cultivo mínimo estar associado ao conceito de plantio direto. 
dissecantes para manter a palha como forma de manutenção da umidade do solo (e da matéria orgânica), essencial em cultivos não irrigados do Brasil.

Este processo de contínuo aprendizado depende do trabalho individual e coletivo local, o que propicia externalidades. As vantagens locais são progressivamente transferidas aos outros agricultores como efeito de transbordamento da necessidade de introdução de novos equipamentos. Todavia, é óbvio que os produtores com maior acumulação de conhecimento possuem ganho diferencial em relação àqueles que dependem do conhecimento tácito, que é embarcado na forma de máquinas e de resultados das pesquisas da Empresa Brasileira de Pesquisa Agropecuária (Embrapa).

A associação dos produtores de plantio direto (na palha) tem cerca de 40 anos. Os agricultores inovadores diversificaram suas atividades e elevaram os seus lucros, gerando efeitos de transbordamento para a agricultura local e países vizinhos, como Paraguai e Argentina. O plantio direto abrange uma área significativa da produção brasileira (25 milhões de hectares), sendo também desenvolvido na canade-açúcar.

Este exemplo mostra que a coevolução das tecnologias agrícolas depende fundamentalmente do esforço local de desenvolvimento. Ainda que melhorias do plantio direto tenham passado por modelos experimentais - e, portanto, pela pesquisa feita em instituições de pesquisa - a percepção do problema e das oportunidades tecnológicas para o desenvolvimento de tecnologias com forte interação local partiu fundamentalmente dos agricultores.

A difusão da soja transgênica na Argentina e no Brasil tem história interessante que corrobora o papel ativo dos agricultores e dos produtores de sementes, que devem ser encarados como agricultores especializados e geralmente inovadores $^{26}$. Este exemplo mostra que o papel ativo dos agricultores está em aproveitar as oportunidades tecnológicas, mais do que atuar como agente schumpeteriano tradicional. $\mathrm{O}$ sentido de inovar ou imitar é combinar adequadamente tecnologias que possam gerar vantagens locais duradouras.

Em meados de 1990, a Monsanto transferiu material tolerante a herbicida às empresas locais Relmó e Nidera (grupo holandês de óleos instalado na Argentina), abrindo mão da cobrança de royalties. $\mathrm{O}$ desenvolvimento dos cultivares implicava no aproveitamento da tolerância a certos herbicidas hormonais de várias plantas. Portanto, a ideia desenvolvida pela Monsanto era genérica, mas a apropriação local das vantagens tecnológicas dependeu do papel ativo dos agricultores.

A difusão poderia ser encarada conforme a teoria, em que o potencial das sementes geneticamente modificadas foi paulatinamente disseminado. O problema

(26) Para um estudo do caso argentino, vide Trigo et al. (2002). 
estava na dificuldade do manejo de ervas daninhas na região combinada às limitações impostas à expansão da soja na Argentina pela disponibilidade de terras. $\mathrm{O}$ fato inovador foi que a expansão da tecnologia deu-se de forma a acelerar e consolidar o plantio direto no país, um esforço feito em colaboração com instituições de pesquisa locais, Embrapa e inclusive com a participação de associação de produtores. O potencial produtivo da semente amplia a partir do momento que se melhoram as condições do manejo do solo e suas respectivas propriedades. A participação ativa dos produtores na difusão resultou não só no equacionamento do problema, mas possibilitou intensificar o uso do solo nas regiões produtoras, gerando competitividade à agricultura argentina, que tem vantagens competitivas relacionadas à logística frente ao competidor direto, Brasil.

O plantio direto e o cultivo de transgênicos reforçam a hipótese estudada, na qual a atividade agrícola busca a combinação eficiente dos insumos industriais, que não se alcança apenas com pesquisas especializadas, mas com formas integradas de experimentação, onde aprendizado local e capacidade de absorver conhecimento são requisitos.

A adoção tecnológica estimula o comportamento do carona, já que a informação do gerenciamento da nova técnica produtiva ${ }^{27}$ é não excludente (característica inerente ao fato de não existirem custos adicionais de repasse do conhecimento a um produtor extra). A produtividade adquirida via adoção é incerta e dependente de fatores endógenos e exógenos. O transbordamento do conhecimento associado ao aprendizado dos outros é reduzido em um primeiro instante. Foster e Rosenzweig (1995) indicaram que não existe coordenação suficiente para a adoção de novos conhecimentos e, nesse caso, cabe ao Estado subsidiar investimentos iniciais dos agentes inovadores (ou first movers).

Segundo Oltra (1997, p. 6), “(...) l'accroissement des capacités d'aprentissage et d'accumulation de connaissances des firmes est un objectif fondamental des politiques technologiques, qui s'inscrit à la fois dans une perspective d'innovation et de diffusion". As políticas públicas de desenvolvimento valorizam as interações entre pesquisa científica e tecnologia. Todavia, a eficácia da transferência tecnológica depende da capacidade de absorção das organizações. A incorporação do Cerrado brasileiro à produção agrícola, a introdução do plantio direto e o cultivo de transgênicos foram resultados de esforço público no provimento de pesquisa e conhecimento combinado ao aprendizado local e à capacidade de absorção do conteúdo externo pelos agricultores.

As trajetórias tecnológicas, induzidas pelos preços relativos dos insumos ou mesmo por alterações institucionais, bem como a capacidade diferenciada dos

(27) Por exemplo, o uso de inoculantes, a medida adequada de calcário que faça correção da acidez do solo e as novas variedades com rendimentos mais elevados. 
agricultores em assimilar e explorar o conhecimento externo (para não mencionar as especificidades climáticas, biológicas e geográficas), proporcionam uma dinâmica favorável ao agricultor inovador.

\section{Considerações finais}

O presente trabalho procurou discutir referenciais teóricos de análise do comportamento do moderno setor agrícola. As competências organizacionais, a trajetória tecnológica e o aprendizado localizado são relevantes para a compreensão da dinâmica do crescimento produtivo na agricultura. A tese estruturalista de desenvolvimento baseada nas trocas desiguais de comércio internacional não explica o comportamento do moderno setor agrícola, o qual é capaz de gerar progresso técnico e valor agregado, bem como justificar o crescimento de regiões dinâmicas agroexportadoras - o paradoxo de Prebisch.

$\mathrm{O}$ arcabouço teórico referente à TTA indica a forma de estudar o sistema agrícola. Em linhas gerais, embora o desenvolvimento tecnológico seja elaborado parcialmente no setor fornecedor de insumos, a dinâmica da produção agrícola influencia as trajetórias tecnológicas futuras. Os agricultores competem por uma melhor e mais eficiente combinação de insumos produtivos a ponto de adquirir vantagens comparativas dinâmicas. $\mathrm{O}$ investimento gera inovações tecnológicas, mas fundamentalmente, no caso agrícola, aumento na capacidade de absorção de conhecimento externo.

O agricultor é capaz de promover descontinuidades tecnológicas que impactam toda a cadeia produtiva. As habilidades gerenciais são construídas para explorar e captar novas informações. Portanto, o processo de adoção tecnológica condiciona os parâmetros da difusão, e não o contrário. O setor agrícola pode ampliar as oportunidades tecnológicas dos fornecedores de insumos modernos. O efeito de ação e reação em cadeia proporciona crescimento em nichos tecnológicos, estabelecendo caminhos e trajetórias bem definidas.

A inovação não implica somente na aquisição de informações de processos acerca de novos produtos ou técnicas, mas na existência da gestão do conhecimento tácito e específico incorporado nos insumos. A capacidade de inovar depende dos conhecimentos gerenciais. O produtor investe no intuito de aumentar o aprendizado e a capacidade de absorção de conhecimento. O estudo aponta para a importância das fontes externas de conhecimento, sendo elevada a produtividade agrícola por intermédio da acumulação de conhecimento, seja pelo aprendizado por meio da experiência e adaptação ou pelo transbordamento do conhecimento em rede.

Aumentar a produtividade da agricultura não é simplesmente ajustar os parâmetros da difusão, já que estes são influenciados pela dinâmica produtiva. O processo de modernização agrícola não se insere em uma lógica de setor retardatário, 
em que o progresso técnico deteriora a renda do agricultor. A indução tecnológica se associa aos elementos schumpeterianos de análise e às mudanças institucionais. A agricultura não pode ser considerada um segmento dominado pelos fornecedores, sem a inclusão do enfoque sistêmico que incorpore a aprendizagem, a geração e a difusão de conhecimento.

\section{Referências bibliográficas}

ACHILLADELIS, B.; SCHWARZKOPF, A.; CINES, M. The dynamics of technological innovation: the case of the chemical industry. Research Policy, v. 19, n. 1, p. 1-34, 1990.

ALCHIAN, A. A.; DEMSETZ, H. Production, information costs, and economic organization. The American Economic Review, v. 62, n. 5, p. 777-795, 1972.

ALLEN, D. W.; LUECK, D. The nature of the farm. Journal of Law and Economics, v. 41, n. 2, p. 343-386, 1998.

AOKI, M. Three-level approach to the rules of societal game: generic, substantive and operational. [s.1; s.n.], 2007.

BARDHAN, P.; UDRY, C. Technological progress and learning. In: DEVELOPMENT microeconomics. New York: Oxford University Press, 1999. chapt. 12, p. 152-167.

BARZEL, Y. Standards and the form of agreement: 2002 presidential address western economic association. Economic Inquiry, v. 42, n. 1, 2004.

BELIK, W. Políticas de segurança alimentar e nutrição na América Latina. São Paulo: Hucitec, 2004.

BELL, M.; PAVITT, K. Technological accumulation and industrial growth: contrasts between developed and developing countries. Industrial and Corporate Change, v. 2, n. 2, p. 157-210, 1993.

BISANG, R.; VARELA, L. Panorama internacional da biotecnologia en el sector agrario. In: BISANG, R.; GUTTMANN, G.; LAVARELLO, P.; SZTUWARK, S.; DIAS, Y. A. (Ed.). Biotecnologia y desarrolloe: um modelo para armar en Argentina. Buenos Aires: Prometeo Libros, 2008. p. 25-62.

BRESCHI, S.; MALERBA, F.; ORSENIGO, L. Technological regimes and Schumpeterian patterns of innovation. The Economic Journal, v. 110, n. 463, p. 388-410, 2000.

BROUSSEAU, E.; RAYNAUD, E. Climbing the hierarchical ladders of rules: the dynamics of institutional framework. Paris: West University Nanterre La Défense $\mathrm{X}, 2008$. 
BUAINAIN, A. M., SOUZA FILHO, H. M.; Silveira, J. M. F. Inovação tecnológica na agricultura e a agricultura familiar. In: Inovação nas tradições da agricultura familiar, D. M. de Albuquerque Lima; J. Wilkinson, ed. Paralelo15. 2002

CEPAL. La hora de la igualdad: brechas por cerrar, caminhos por abrir. Santiago de Chile: Comissão Econômica para o Desenvolvimento da América Latina e do Caribe, 2010.

CHIAROMONTE, F.; DOSI, G. The micro foundations of competitiveness and their macroeconomic implications. In: FREEMAN, C.; FORAY, D. (Ed.). Technology and the wealth of nations: the dynamics of constructed advantages. London: Pinter Publishers, 1992. p. 107-134.

CIMOLI, M. Heterogeneidad structural asimetrías tecnológicas y crescimiento en América Latina. Santiago de Chile: Cepal, 2005.

CIMOLI, M.; PRIMI, A.; PUGNO, M. Um modelo de bajo crecimiento: la informalidade como restricción estructural. Revista de la Cepal, v. 1, n. 88, p. 89107, 2006.

COCHRANE, W. W. Farm prices: myth and reality. Minneapolis: University of Minnesota Press, 1958.

COHEN, W. M.; LEVINTHAL, D. A. Innovation and learning: the two faces of R\&D. The Economic Journal, v. 99, n. 397, p. 569-596, 1989.

COWAN, R.; JONARD, N. The dynamics of collective invention. Journal of Economic Behavior and Organization, v. 52, p.513-532, 2003.

DOSI, G. Technical change and industrial transformation. New York: St. Martin's Press, 1984.

DOSI, G. Sources, procedures, and microeconomic effects of innovation. Journal of Economic Literature, v. 26, n.3, p. 1120-1171, 1988.

DOSI, G.; FAILLO, M.; MARENGO, L. Organizational capabilities, patterns of knowledge accumulation and governance structures in business firms: an introduction. Pisa, Italy: Laboratory of Economics and Management / Sant'Anna School of Advanced Studies, 2003. (Paper Series, 2003/11).

ESPOSTI, R. Public agricultural R\&D design and technological spill-ins: a dynamic model. Research Policy, v. 31, n. 5, p. 693-717, 2002.

EVENSON, R. E.; KISLEV, Y. Research and productivity in wheat and maize. Journal of Political Economy, v. 81, n. 6, p. 1309-1329, 1973.

FAO. La situation mondiale de l'alimentation et de l'agriculture. [s.1.]: The State of Food and Agriculture - SOFA / Food Agriculture Organization, 2000. 
FAVARETO, A. S. Paradigmas do desenvolvimento rural em questão. São Paulo: Iglu. 2007

FLIGSTEIN, N. Myths of the market. In: EBNER, A.; BECK, N. (Ed.). The institutions of the market: organizations, social systems, and governance. NewYork: Oxford University Press, 2008.

FORAY, D. Les modèles de competition technologique: une revue de la littérature. Revue d'Économie Industrielle, v. 48, n. 1, p. 16-34, 1989.

FORNAZIER, A.; VIEIRA FILHO, J. E. R. Heterogeneidade estrutural no setor agropecuário brasileiro: evidências a partir do censo agropecuário de 2006. Brasília: Ipea, 2012. (Texto para Discussão, n. 1708).

FOSS, K.; FOSS, N. Assets, attributes, and owership. [s.1.]: Institut for Industriøkonomi og Virksomhedsstrategi, 2000. (Technical Report).

FOSTER, A. D.; ROSENZWEIG, M. R. Learning by doing and learning from others: human capital and technical change in agriculture. Journal of Political Economy, v. 103, n. 6, p. 1176-1209, 1995.

GASQUES, J. G.; BASTOS, E. T.; BACHI, M. R. P.; VALDES, C. Produtividade total dos fatores e transformações da agricultura brasileira: análise dos dados dos censos agropecuários. In: GASQUES, J. G.; VIEIRA FILHO, J. E. R.; NAVARRO, Z. (Ed.). A agricultura brasileira: desempenho, desafios e perspectivas. Brasília: Ipea, 2010. Chapt. 1, p. 19-44.

GASQUES, J. G.; RESENDE, G. C., VERDE, C. M. V., SALERMO, M. S., CONCEIÇÃO, J. C. P. R.; CARVALHO, J. C. S. Desempenho e crescimento do agronegócio no Brasil. Brasília: Ipea, 2004. (Texto para Discussão, n. 1009).

GYLFASON, T.; ZOEGA, G. Natural resources and economic growth: the role of investment. The World Economy, v. 29, n. 8, p. 1091-1115, 2006.

HAYAMI, Y. K.; RUTTAN, V. W. Agricultural development: an international perspective. rev. ed. Baltimore: Johns Hopkins University Press, 1985.

JOHNSON, D. K. N.; EVENSON, R. E. How far away is Africa? Technological spillovers to agriculture and productivity. American Agricultural Economics Association, v. 82, p.743-749, 2000.

KATZ, J. Reformas estructurales, productividad y conducta tecnológica. Santiago de Chile: Cepal, 2000.

KLEVORICK, A. K., LEVIN, R. C., NELSON, R. R.; WINTER, S. G. On the sources and significance of interindustry differences in technological opportunities. Research Policy, v. 24, n. 2, p. 185-205, 1995. 
MALERBA, F. Sectoral system of innovation and production. Research Policy, v. 31, n. 2, p. 247-264, 2002.

MALERBA, F.; ORSENIGO, L. Schumpeterian patterns of innovation are technology-specific. Research Policy, v. 25, n. 3, p. 451-478, 1996.

MATTSON, J.; KOO, W. W. Forces reshaping world agriculture., Fargo, ND: North Dakota State University. 2006. (Agribusiness Applied Economics Report, n. 582).

MAZOYER, M.; ROUDART, L. História das agriculturas do mundo: do neolítico à crise contemporânea. [s.1.]: Instituto Piaget, 2001 .

MELLO, F. H. Agricultura, energia e recessão econômica. Revista de Economia Política, v. 3, n. 2, p. 51-67, 1983.

METCALFE, J.S. Evolutionary economics and creative destruction. 3. ed. London: Routledge, 2002.

MOWERY, D. C.; ROSENBERG, N. Trajetórias da inovação: a mudança tecnológica nos Estados Unidos da América no século XX. Campinas: Unicamp, 2005.

MURAKAMI, T. G. L. As redes de valor do conhecimento como geradoras e difusoras do progresso técnico para atividades agropecuárias: o caso da avicultura brasileira. Thesis (Master)-Unicamp, Campinas, 2010.

NELSON, R. R.; WINTER, S. G. In search of useful theory of innovation. Research Policy, v. 6, n. 1, p. 36-76, 1977.

NELSON, R. R.; WINTER, S. G. An evolutionary theory of economic change. Massachusetts: Harvard University Press, 1982.

NOHLEN, D.; STURM, R. La heterogeneidad estructural como concepto básico en la teoría de desarrollo. Revista de Estudos Políticos, v. 1, n. 28, p. 45-74, 1982.

OLTRA, V. Politiques technologiques et dynamique industrielle. Thesis (PhD)Faculte dês Sciences Economiques et de Gestion, Université Louis Pasteur Strasbourg I, 1997.

PARADYIL, G. The green revolution in India: a case study in technological change. Technology and Culture, v. 33, n. 4, p.737-756, 1992.

PARADYIL, G. Mapping technological trajectories of the green revolution and the gene revolution from modernization to globalization. Research Policy, v. 32, p. 971-990, 2003.

PAVITT, K. Sectoral patterns of technical change: towards a taxonomy and a theory. Research Policy, v. 13, n. 6, p. 343-373, 1984. 
PEREZ, C. Dinamismo tecnológico e inclusión social en America Latina: uma estratégia de desarrollo productivo baseada en recursos naturales. Revista de la Cepal, v. 1, n. 100, p. 123-145, 2010.

PINTO, A. Natureza e implicações da heterogeneidade estrutural da América Latina. El Trimestre Económico, v. 37, n. 1, (145), 1970.

POSSAS, M. L.; SALLES-FILHO, S.; SILVEIRA, J. M. An evolutionary approach to technological innovation in agriculture: some preliminary remarks. Research Policy, v. 25, n. 6, p. 933-945, 1996.

PREBISCH, R. O desenvolvimento econômico da América Latina e alguns de seus problemas principais. In: BIELSCHOWSKY, R. Cinquenta anos de pensamento da Cepal. Rio de Janeiro: Record, 2000. p. 69-136.

SADOULET, E.; DE JANVRY, A. Transactions costs and agrarian institutions. In: SADOULET; E.: DE JANVRY, A. (Ed.). Quantitative development policy analysis. Baltimore, Maryland: The Johns Hopkins University Press, 1995. Chapt. 9, p. 241272.

SAHAL, D. Patterns of technological innovation. Boston: Addison-Wesley, 1981.

SAHAL, D. Technological guideposts and innovation avenues. Research Policy, v. 14, n. 2, p. 61-82, 1985.

SILVEIRA, J. M. F.; BORGES, I. C.; FONSECA, M. G. D. Biotecnologia e desenvolvimento de mercados: novos desafios, novos conceitos? In: RAMOS, P. (Ed.). Dimensões do agronegócio brasileiro: políticas, instituições e perspectivas. Brasília: Ministério do Desenvolvimento Agrário, 2007. p. 318-357.

SMEDSHAUG, C. A. Feeding the world in the 21st century: a historical analysis of agriculture and society. London: Anthem Press, 2010.

SUNKEL, O.; INFANTE, R. Hacia un desarrollo inclusivo el caso de Chile. Santiago de Chile: Cepal, 2009.

TAVARES, M. C. Da substituição de importações ao capitalismo financeiro: ensaios sobre a economia brasileira. Rio de Janeiro: Zahar, 1972.

TEECE, D. J. Economies of scope and the scope of the enterprise. Journal of Economic Behavior and Organization, v. 1, n. 3, p. 223-247, 1980.

TEECE, D. J.; PISANO, G.; SHUEN, A. Dynamic capabilities and strategic management. Strategic Management Journal, v. 18, n. 7, p. 509-533, 1997.

TRIGO, E.; CHUDNOVSKY, D.; CAP, E.; LÓPEZ, A. Genetically modified crops in Argentine agriculture: an open ended story. Buenos Aires: Libros del Zorzal, 2002. 
VEIGA, J. E. Uma linha estratégica de desenvolvimento agrícola. Revista de Economia Política. v. 12, n. 2, p. 88-105, abr./jun. 1992.

VIEIRA FILHO, J. E. R. Technological trajectories and learning in agricultural sector. In: THE GLOBELICS International Conference, 10th, 2012.

VIEIRA FILHO, J. E. R. Heterogeneidad estructural de la agricultura familiar en el Brasil. Revista de la Cepal, v. 111, p. 103-121, 2013.

VIEIRA FILHO, J. E. R. Inovação tecnológica e aprendizado agrícola: uma abordagem schumpeteriana. Tese (Doutorado)-Universidade Estadual de Campinas, Campinas, 2009.

VIEIRA FILHO, J. E. R.; SILVEIRA, J. M. F. Modelo evolucionário de aprendizado agrícola. Revista Brasileira de Inovação, v. 10, n. 2, p. 265-300, 2011.

VIEIRA FILHO, J. E. R.; CAMPOS, A. C.; FERREIRA, C. M. C. Abordagem alternativa do crescimento agrícola: um modelo de dinâmica evolucionária. Revista Brasileira de Inovação, v. 4, n. 2, p. 425-476, 2009.

VIEIRA FILHO, J. E. R.; SANTOS, G. R.; FORNAZIER, A. Distribuição produtiva e tecnológica da agricultura brasileira e sua heterogeneidade estrutural. Brasília: Cepal/Ipea, 2013. (Texto para Discussão, n. 54).

WORLD BANK. Agriculture for development. World Development Report 2008, Washington, DC: World Bank, 2008.

WRIGHT, B. D. Grand missions of agricultural innovation. Research Policy, n. 41 , p. 1716-1728, 2012. 